\title{
Clean 3,4-Dihydropyrimidones Synthesis via Biginelli Reaction over Supported Molybdenum: Structural and Textural Characteristic of $\mathrm{aMoO}_{3}$
}

\author{
Ouzna Kheffache ${ }^{1,2, *}$, Cristina Lopez-Olmos ${ }^{3}$, Inmaculada Rodriguez-Ramos ${ }^{3}$, Ouiza Cherifi ${ }^{1}$ \\ ${ }^{1}$ Laboratoire de Chimie du Gaz Naturel, Faculté de Chimie, Université des Sciences et de la Technologie \\ Houari Boumediène, USTHB, PB 32, 16111, El Alia, Bab-Ezzouar, Alger, Algérie \\ ¿Université d'Alger I, 02 Rue Didouche Mourad, 16000 Alger Centre, Algérie \\ ${ }^{3}$ Instituto de Catálisis y Petroleoquímica, CSIC, C/Marie Curie 2, Cantoblanco, 28049 Madrid, Spain
}

Received: $5^{\text {th }}$ July 2020; Revised: $14^{\text {th }}$ August 2020; Accepted: $15^{\text {th }}$ August 2020;

Available online: $15^{\text {th }}$ September 2020; Published regularly: December 2020

\begin{abstract}
A one-pot three-component synthesis of dihydropyrimidinones (DHPMs) via Biginelli reaction was carried out at $100{ }^{\circ} \mathrm{C}$ using benzaldehyde, ethyl acetoacetate and urea as reactants, in the presence of ethanol and free solvent, in heterogeneous catalytic medium. The Mo (30 wt\%) metal oxides $\left(\mathrm{Al}_{2} \mathrm{O}_{3}, \mathrm{SiO}_{2}\right.$ or $\mathrm{MgO}$ ) used catalysts were prepared by sol-gel, impregnation and microemulsion methods and characterized by X-Ray Diffraction (XRD), Fourier Transform Infra Red (FTIR), Scanning Electron Microscopy (SEM), Transmission Electron Microscopy (TEM), Energy Dispersive X-ray (EDX), Nitrogen Adsorption - Brunauer-Emmett-Teller (BET), and $\mathrm{NH}_{3}$-Temperature Programmed Desorption (TPD) methods. The Mo-SiO $\mathrm{M}_{2}$ sample prepared by the sol-gel method exhibited the highest DHPM yield (87\%), in free solvent with a reaction time of $30 \mathrm{~min}$. The high efficiency, in the Biginelli reaction, of the Mo$\mathrm{SiO}_{2}$ catalyst is due to its structural, textural and acid properties. Highly dispersed aMoO $\mathrm{species} \mathrm{of}_{3}$ orthorhombic structure having a high contribution of strong acidic sites would be the active species in the Biginelli synthesis Copyright (C) 2020 BCREC Group. All rights reserved
\end{abstract}

Keywords: Heterogeneous catalysis; Biginelli reaction; Green chemistry; $\mathrm{aMoO}_{3} ; \mathrm{SiO}_{2}$

How to Cite: Kheffache, O., Lopez-Olmos, C., Rodriguez-Ramos, I., Cherifi, O. (2020). Clean 3,4-

Dihydropyrimidones Synthesis via Biginelli Reaction over Supported Molybdenum: Structural and Textural Characteristic of $\mathrm{aMoO}_{3}$. Bulletin of Chemical Reaction Engineering \& Catalysis, 15(3), 698-713 (doi:10.9767/bcrec.15.3.8264.698-713)

Permalink/DOI: https://doi.org/10.9767/bcrec.15.3.8264.698-713

\section{Introduction}

The Biginelli synthesis is a multicomponent reaction that gives access, in a single operation, to molecule formation with several functions. This process also permits saving atoms, reduc-

* Corresponding Author.

E-mail: kheffacheo@yahoo.fr (O. Kheffache)

Tel: +2135520132 66; Fax: +21321248008 ing both time and energy and also limiting waste and risks. In recent years, dihydropyrimidinones (DHPMs) and their derivatives Biginelli compounds, are being widely studied because of their biological, therapeutic and pharmaceutical properties, such as: antiviral, antibacterial, anti-inflammatory and antitumor activities [1-3]. It has been also reported that functionalized dihydropyrimidinones were used as antihypertensive agents, calcium channel 
blockers, adrenergic and neuro peptide Y (NPY) antagonists [4-5]. One of the principal multicomponent reactions (MCRs), dihydropyrimidinones (DHPMs) synthesis, was reported by P. Biginelli (19 $9^{\text {th }}$ Century). This reaction is defined as a process for assembling on one pot three reagents: benzaldehyde, ethyl acetoacetate and urea under strongly acidic conditions. However, this protocol presents several disadvantages such as the use of organic solvents, extensively long reaction times (from 24 to $36 \mathrm{~h}$ ) and high reaction temperatures, leading frequently to low product yields $(20-60 \%)$, particularly in the case of substituted aromatic and aliphatic aldehydes [6]. In order to enhance the yields of Biginelli reaction, various catalysts, such as: Lewis acids [7-14], Brønsted mineral acids [15-17], heteropolyacids [18-19], Brønsted bases [20,21] and organometallic [22-24], were used, generally in homogeneous phase and sometimes under the assistance of microwave [25] or ultrasound irradiation. To overcome the disadvantages of the homogeneous medium such as corrosion, pollution and waste, the development of heterogeneous catalysts has been the objective of several works [26-27]. For example, Gupta et al. [28] reported the use of sulfonic acid covalently anchored onto silica as an efficient heterogeneous catalyst for the one-pot synthesis of 3,4-dihydropyrimidinones. However, high reaction times between 8 and 12 hours were registered to achieve good yields of reaction products; which limited the utility of this method.

Among the solid catalysts, those based on Mo oxides have been widely used in diverse organic reactions, such as: nitration [29], condensation [30], hydrodesulfurization [31], and transesterification [32]. Otherwise, they were found very effective in the synthesis of dihydropyrimidinones (DHPMs) and of their derivatives [33,34]. Nevertheless, it was underlined over these researches performed on the Mo based systems, that the catalytic performance of these materials depends on the metal loading, the nature of the support $\left(\mathrm{SiO}_{2}, \mathrm{Al}_{2} \mathrm{O}_{3}\right.$, etc.) and the preparation method. In addition to the impregnation method, which is the most widely used because of its simplicity, sol-gel and co-precipitation procedures have been also used.

In this context, this work reports the use of Mo as an active phase combined to different metal oxides $\left(\mathrm{Al}_{2} \mathrm{O}_{3}, \mathrm{MgO}, \mathrm{SiO}_{2}\right)$ as heterogeneous efficient catalysts in the DHPM synthesis via the Biginelli reaction. This study aims not only to examine the effect of the nature of metal oxide, but also discusses the influence of the preparation method on the physicochemical and catalytic properties, carried out on the most active catalyst which is $\mathrm{Mo}-\mathrm{SiO}_{2}$ sample prepared by three different methods (impregnation, sol-gel and microemulsion). The effects of the solvent, reaction time and temperature on DHPM yield were also examined in order to determine the optimum operating conditions of the Biginelli reaction over the elaborated Mo-based catalysts.

\section{Materials and Methods}

\subsection{Catalyst Preparation}

Supported molybdenum (30\%) on $\mathrm{SiO}_{2}$, $\mathrm{Al}_{2} \mathrm{O}_{3}$ and $\mathrm{MgO}$ were prepared by sol-gel (noted MoSi-SG, MoAl-SG, and MoMg-SG), impregnation (noted MoSi-IMP) and micro-emulsion (noted MoSi-ME).

\subsubsection{Used precursors}

Different commercial salts and reactants were used as precursors in our catalysts preparations: $\mathrm{H}_{24} \mathrm{Mo}_{7} \mathrm{~N}_{6} \mathrm{O}_{24} \cdot 4 \mathrm{H}_{2} \mathrm{O}$ (98\%, BiochemChemopharma), $\mathrm{Al}\left(\mathrm{NO}_{3}\right)_{3} \cdot 9 \mathrm{H}_{2} \mathrm{O}$ (98.5\%, RiedelHaën $\left.{ }^{\circledR}\right)$, Tetraethylorthosilicate TEOS (98\%, Sigma Aldrich), $\mathrm{Mg}\left(\mathrm{NO}_{3}\right)_{2} \cdot 6 \mathrm{H}_{2} \mathrm{O}$ (97\%, RiedelHaën () , Citric acid (< 99\%, Riedel-Haën $\AA)$, Ammonium hydroxide (30\%, Panreac), Cyclohexane (99.8 \%, Riedel- de Haen), Butanol (99.5\%, Riedel-de Haen), Triton 100-x (99\%, Biochem Chemopharma), Ethanol (99.8\%, Sigma - Aldrich).

\subsubsection{Preparation procedures}

Sol-gel method (SG): a mixture constituted of $\mathrm{H}_{24} \mathrm{Mo}_{7} \mathrm{~N}_{6} \mathrm{O}_{24} \cdot 4 \mathrm{H}_{2} \mathrm{O}\left(4.5 .10^{-3} \mathrm{~mol}\right)$ and $\mathrm{Al}\left(\mathrm{NO}_{3}\right)_{3} .9 \mathrm{H}_{2} \mathrm{O}(0.14 \mathrm{~mol})$, tetraethylorthosilicate TEOS $(0.1 \mathrm{~mol})$ or $\mathrm{Mg}\left(\mathrm{NO}_{3}\right)_{2} \cdot 6 \mathrm{H}_{2} \mathrm{O}(0.17$ mol) was dissolved in $20 \mathrm{~mL}$ of distilled water. Then, a saturated solution of citric acid was added to the aqueous solution. This latter was stirred and heated at $100{ }^{\circ} \mathrm{C}$ until gel formation. The resulting gel was dried at $100{ }^{\circ} \mathrm{C}$ for $12 \mathrm{~h}$ and calcined at $500{ }^{\circ} \mathrm{C}$ during $4 \mathrm{~h}$. The different samples were noted: MoAl-SG, MoSi$\mathrm{SG}$, and MoMg-SG.

Impregnation method (IMP): the silica support was prepared according to literature procedure [35]. A mixture of tetraethylorthosilicate TEOS and ammonium hydroxide (1 M) was heated at $100{ }^{\circ} \mathrm{C}$ under agitation until gel formation. The gel was washed, filtered and dried at $100{ }^{\circ} \mathrm{C}$ for $12 \mathrm{~h}$ then calcined at $600{ }^{\circ} \mathrm{C}$ during $4 \mathrm{~h}$. $\mathrm{Mo}_{-} \mathrm{SiO}_{2}$ (noted MoSi-IMP) was prepared by wet impregnation of $\mathrm{H}_{24} \mathrm{Mo}_{7} \mathrm{~N}_{6} \mathrm{O}_{24} \cdot 4 \mathrm{H}_{2} \mathrm{O}$ on silica, dried at $100{ }^{\circ} \mathrm{C}$ for $12 \mathrm{~h}$ and calcined at $500{ }^{\circ} \mathrm{C}$ during $4 \mathrm{~h}$. 
Microemulsion method (ME): two solutions were prepared; the first (microemulsion A) containing, $38 \mathrm{~mL}$ of cyclohexane, $8.4 \mathrm{~mL}$ of butanol, $9.6 \mathrm{~mL}$ of Triton $100-\mathrm{x}$, (used as a surfactant), $2.3 \times 10^{-3} \mathrm{~mol}$ of ammonium heptamolybdate and $24 \mathrm{~mL}$ of TEOS; and the second one (microemulsion B) contains the same reactants but ammonium heptamolybdate and tetraethylorthosilicate were replaced by $10 \mathrm{~mL}$ of ammonium hydroxide. Each microemulsion was stirred for $1 \mathrm{~h}$ at room temperature. Then, microemulsion $\mathrm{B}$ was added to the microemulsion A under rigorous agitation at room temperature for $24 \mathrm{~h}$. The resulting suspension was filtered and washed with ethanol. The obtained solid (denoted as MoSi-ME), was dried for $12 \mathrm{~h}$ at room temperature and calcined at $500{ }^{\circ} \mathrm{C}$ for $4 \mathrm{~h}$.

\subsection{Characterization Techniques}

X-ray diffraction (XRD) patterns of samples were recorded on a Bruker AXS-D8 diffractometer with a Cu- $\mathrm{K}_{a}$ irradiation source $(\lambda=1.5406$ $\AA$ ). The scan range varied between 10 and $90^{\circ}$ with a $0.020^{\circ}$ step and an acquisition time of $0.80 \mathrm{~s}$ at each step. The infrared spectra were recorded using an Alpha Bruker spectrometer over a range of $4000-400 \mathrm{~cm}^{-1}$. The specific surface ( $\left.S_{\mathrm{BET}}\right)$ of the material was determined by nitrogen adsorption-desorption at $77 \mathrm{~K}$ using a Micromeritics ASAP 2420 instrument. Before analysis, the sample was outgassed under vacuum at $250{ }^{\circ} \mathrm{C}$ for $12 \mathrm{~h}$. The specific surface values were determined by BET method in the range $P / P_{0}$ of $0.05-0.30$.

In order to obtain information on morphological characteristics, the catalysts were subjected to a detailed scanning electron microscopy (SEM) study using a Hitachi TM-1000apparatus. TEM analyses were performed on a JEOL $2100 \mathrm{~F}$ field emission electron gun microscope operated at $200 \mathrm{kV}$ and equipped with an Energy-Dispersive X-Ray detector. The sample was ground to powder and a small amount was suspended in ethanol solution using an ultrasonic bath. Some drops of the resulting suspension were added to the copper grid (Aname, Lacey carbon 200 mesh) and the ethanol was evaporated at room temperature before introducing the sample holder into the microscope. The Scanning Transmission Electron Microscopy (STEM) was done using a spot size of $1 \mathrm{~nm}$.

Acidic sites of the solids were determined by temperature programmed desorption (TPD) of $\mathrm{NH}_{3}$ in a flow system Micromeritics Autochem II 2920 equipped with a thermal conductivity detector. Previously, the samples were treated in Helium at $550{ }^{\circ} \mathrm{C}$ and saturated with ammonia gas $5 \%$ at $50{ }^{\circ} \mathrm{C}$, which was swept with $\mathrm{He}$ lium at $100^{\circ} \mathrm{C}$ and then heated from 100 to 550 ${ }^{\circ} \mathrm{C}$ at $10{ }^{\circ} \mathrm{C} / \mathrm{min} .{ }^{1} \mathrm{H}$ NMR $(400 \mathrm{MHz})$ and ${ }^{13} \mathrm{C}$ NMR (100 MHz) spectra were obtained using a Bruker GPX instrument. Chemical shifts $(\delta)$ were reported in parts per million (ppm) relative to residual DMSO, $d 6$, and coupling constant $(J)$ values are given in $\mathrm{Hz}$.

\subsection{Catalytic Test}

A mixture of benzaldehyde $\left(2 \times 10^{-3} \mathrm{~mol}\right)$, ethyl acetoacetate $\left(2 \times 10^{-3} \mathrm{~mol}\right)$, urea $\left(3 \times 10^{-3}\right.$ mol) and catalyst $(0.1 \mathrm{~g})$ was heated at reflux at $100{ }^{\circ} \mathrm{C}$ under rigorous agitation with a reaction time varying from $30 \mathrm{~min}$ to $8 \mathrm{~h}$ (Scheme 1). After reaction, the obtained DHPM product was washed with boiling ethanol and the catalyst was recovered by filtration. After crystallization at $2{ }^{\circ} \mathrm{C}$, the DHPM product was recovered and dried at $100{ }^{\circ} \mathrm{C}$ overnight. The DHPM was identified by attenuated total reflectance (ATR) spectroscopy analysis and ${ }^{13} \mathrm{C}$ Nuclear Magnetic Resonance (NMR).

\section{Results and Discussions}

\subsection{Catalyst Characterization}

The XRD patterns of the prepared samples are presented in Figure 1. Regardless the preparation method, the diffractograms of MoSi and MoAl samples show similar peaks characteristic of $\mathrm{aMoO}_{3}$ oxide crystallizing in an orthorhombic system, observed at $2 \theta=12.7,23.3$,

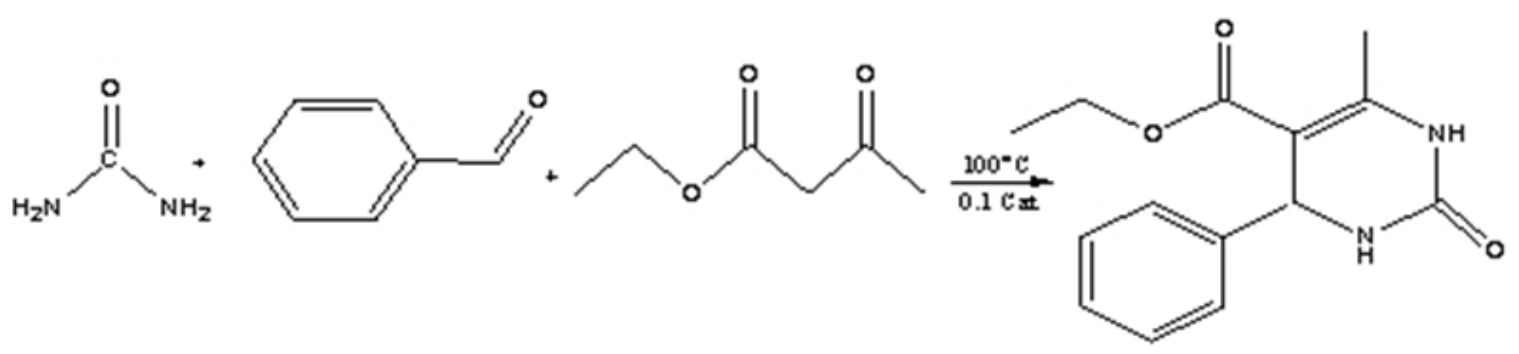

Scheme 1. Biginelli reaction 
25.6, 27.3, and $33.7^{\circ}$ (JCPDS 00-005-0508). It can also be noted that no diffraction lines assigned to the carrier oxide $\left(\mathrm{Al}_{2} \mathrm{O}_{3}\right.$ or $\left.\mathrm{SiO}_{2}\right)$ were detected for these samples. This result is in good agreement with those reported in the literature confirming the formation of bulk molybdenum oxide phase $\left(\mathrm{MoO}_{3}\right)$ when molybdenum loading is higher than 20 weight\% [3638]. Furthermore, no phase corresponding to $\mathrm{BMoO}_{3}$ is observed, probably due to the low calcination temperature of materials [39]. On the other hand, in the case of MoMg-SG, a major $\mathrm{MgO}$ phase was identified at $2 \theta=18.6,28.8$, $42.9,47.1$, and $62.1^{\circ}$ with a presence of $\mathrm{aMoO}_{3}$

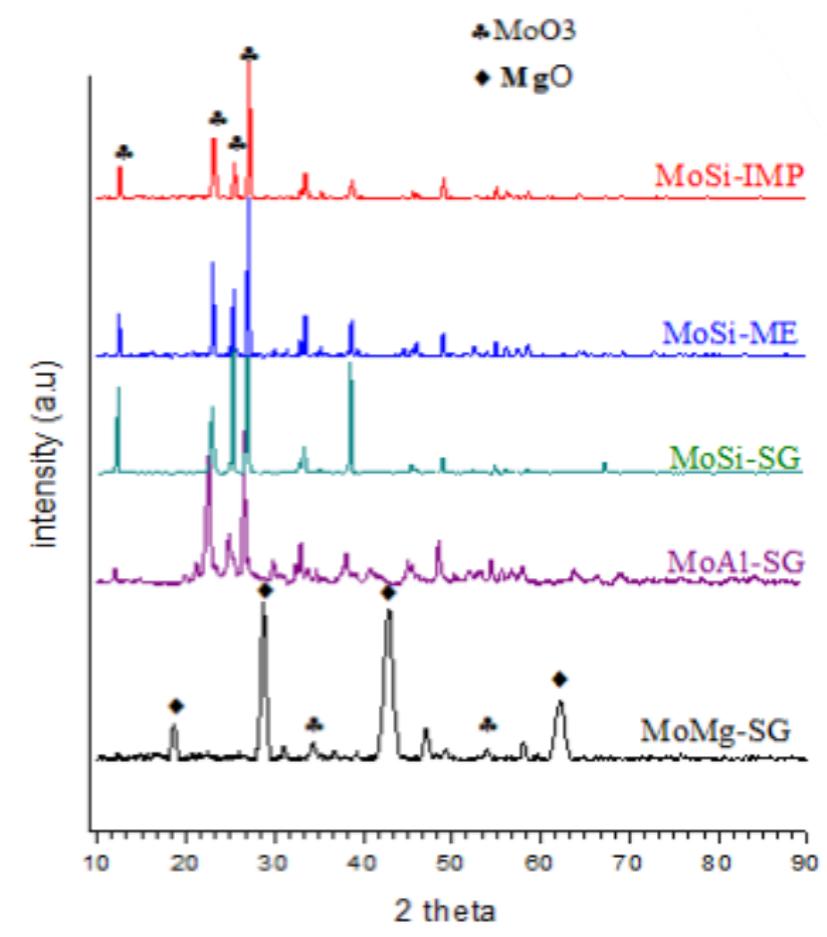

Figure 1. X-ray powder diffraction patterns of the prepared catalysts peaks of low intensity. This can be due to the formation of small crystallites of Mo species on the surface support.

In order to more investigate the structure of our samples and the nature of the Mo species, the FT-IR analysis was carried out (Figure 2). The obtained FT-IR spectra of MoSi prepared by SG, ME, and IMP methods are quite similar. Three intense vibration bands, characteristic of of Si-O-Si [40-41] were identified at around 450,800 et $1060 \mathrm{~cm}^{-1}$. Whilst in the 550-600 and 850-920 $\mathrm{cm}^{-1}$ ranges, the observed vibration bands are assigned to Mo-O-Mo polymolybdate species and that at $994 \mathrm{~cm}^{-1}$ to $\mathrm{Mo}=\mathrm{O}$ groups of the $\mathrm{MoO}_{3}$ phase [42-43], result in agreement to those observed in XRD analysis. For the MoAl-SG and MoMg-SG solids, the same vibration bands corresponding to polymolybdate Mo-O-Mo and $\mathrm{MoO}_{3}$ phase were observed in addition to Mo-O-M ( $\mathrm{M}=\mathrm{Al}$ or $\mathrm{Mg}$ ) band at around $600 \mathrm{~cm}^{-1}$ [44-45].

Indeed, our results seem to be coherent with those observed by Smith et al. on $\mathrm{Mo} / \mathrm{SiO}_{2}$ systems [46] that reported the formation of highly dispersed silicomolybdic species with terminal $\mathrm{Mo}=\mathrm{O}$ sites for low Mo percentage. Whereas, with increasing molybdenum loading, the silicomolybdic species would transform into polymolybdate species, forming Mo-O-Mo bridging sites at the expense of Mo-O sites. These same authors have also confirmed the formation of crystalline $\mathrm{MoO}_{3}$ at high loading of Mo.

Table 1 regroups the textural parameters of the prepared materials. As can be seen, MoSi-SG exhibits the highest specific surface area (132 against $20-85 \mathrm{~m}^{2} / \mathrm{g}$ ), highest pore volume $\left(0.23\right.$ against $\left.0.03-0.20 \mathrm{~cm}^{3} / \mathrm{g}\right)$ and an intermediate pore size (6.9 against 5.5-7.8 nm). The results collected in Table 1 also gave insight on the influence of the synthesis method on the textural properties of MoSi system. The

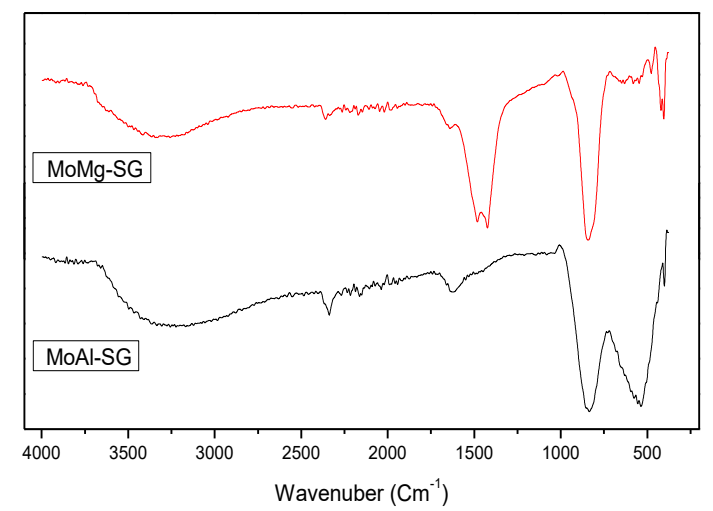

Figure 2. FT-IR spectra of the prepared samples 
obtained values are very sensitive to the preparation procedure; so the microemulsion method permits to obtain the highest values of these different parameters with 205 against 33-132 $\mathrm{m}^{2} / \mathrm{g}$ BET surface area, 0.64 against $0.07-0.23$ $\mathrm{cm}^{3 / \mathrm{g}}$ for pore volume and 13.5 against $6.9-9.1$ $\mathrm{nm}$ pore size. Among the preparation techniques, impregnation is the one that leads to the smallest surface area and pore volume. Similar observations have been obtained for the $\mathrm{Ni} / \mathrm{Al}_{2} \mathrm{O}_{3}$ and $\mathrm{Ni} / \mathrm{CeO}_{2}$ systems $[47,48]$.

Figure 3 displays the nitrogen adsorptiondesorption isotherms of the calcined samples. According to the IUPAC classification [49], the obtained isotherms in the case of MoSi-SG and MoAl-SG solids are similar to type IV, while those of the MoSi-ME, MoSi-IMP, and MoMgSG samples are characteristics of type V. Both types of isotherms indicate the presence of mesopores with pore diameter between 5 and 15 nm (Table 1).

The SEM images presented in Figure 4, reveal that the morphology of the prepared materials is strongly affected by the preparation method and the oxide carrier. Thus, in the case of MoSi system, the sol-gel method leads to the formation of lamellae $\mathrm{aMoO}_{3}$ species, while the microemulsion one gives rise to $\mathrm{aMoO}_{3}$ species in the form of small particles of similar shapes and sizes. On the other hand, the surfaces of MoSi-IMP and MoAl-SG solids are composed of large aggregates whereas a spongy appearance is observed for the MoMg-SG sample.

To further study the morphology and surface composition of the calcined samples, STEM-EDX and FFT analyses of TEM images were carried out on the MoSi system prepared by sol gel and microemulsion, presenting the high activity in the Biginelli test. The TEM images in Figures 5 and 7 of the MoSi sample synthesized by microemulsion and sol-gel respectively, show that molybdenum forms micro-

Table 1. BET surface areas, pore size and pore volume of the elaborated samples.

\begin{tabular}{cccc}
\hline Catalyst & $\begin{array}{c}\text { BET surface } \\
\text { area }\left(\mathrm{m}^{2} / \mathrm{g}\right)\end{array}$ & $\begin{array}{c}\text { Pore size } \\
(\mathrm{nm})\end{array}$ & $\begin{array}{c}\text { Pore volume } \\
\left(\mathrm{cm}^{3} / \mathrm{g}\right)\end{array}$ \\
\hline MoMg-SG & 85 & 7.8 & 0.20 \\
MoAl- SG & 20 & 5.5 & 0.03 \\
MoSi-SG & 132 & 6.9 & 0.23 \\
MoSi-ME & 205 & 13.5 & 0.64 \\
MoSi-IMP & 33 & 9.1 & 0.07 \\
\hline
\end{tabular}

domains of homogeneous size highly dispersed on the silica support; results confirmed by the EDX images (Figures 6 and 8, respectively).

Figure 9 shows a TEM image of the MoSi-SG sample and the corresponding fast Fourier transform patterns of a selected molybdenum microdomain. The FFT pattern demonstrated that the molybdenum microdomain corresponds to $\mathrm{MoO}_{3}$ with an orthorhombic crystal structure (JCPDS file Card No. 05-0508), where the spacing of the lattice of 3.97 and 3.65 $\AA$ can be indexed to the (100) and (001) planes of the orthorhombic $\mathrm{MoO}_{3}$, respectively [50-52]. Moreover, crystalline $\mathrm{SiO}_{2}$ or mixed Mo-Si oxide structures were not detected by the FFT analysis.

The TEM study also revealed that MoSi-SG and MoSi-ME samples form crystalline structures (Figure10), in addition to the Mo microdomains observed in Figures 4 and 5. The crystal structures correspond to molybdenum oxide, as confirmed by EDX elemental mapping (Figure 11). The abundance of these segregated $\mathrm{MoOx}$ crystals is much higher in the sample with a higher Mo charge (MoSi-SG).

Temperature programmed desorption of ammonia was performed for the different samples in order to obtain the distribution of acidic sites that can be seen in Figure 12. The classification of the type of acid sites depends on the $\mathrm{NH}_{3}$ desorption temperature. So, weak acid sites are found between $150-300{ }^{\circ} \mathrm{C}$; moderate acid sites: $300-420{ }^{\circ} \mathrm{C}$ and strong acid sites: $420-600{ }^{\circ} \mathrm{C}$ [53]. Although this values may differ a bit when consulting other literature sources as is found in a literature [54] which identify weak acid sites as those between $100-250{ }^{\circ} \mathrm{C}$; moderate $250-350{ }^{\circ} \mathrm{C}$ and strong acid sites: $350-550$ ${ }^{\circ} \mathrm{C}$.

Bearing this in mind, in our study the peak maximum in most samples is between 180-210 ${ }^{\circ} \mathrm{C}$ indicating the higher proportion of weak acid sites. On the other hand, the peak width and envelope shape differ from one sample to another. Broad peaks indicate wide distribution of acid sites with different strength. This would be particularly interesting for MoSi-SG sample, where the participation of stronger acid sites is deduced from its profile, since it is the only sample noticeably desorbing ammonia above $250{ }^{\circ} \mathrm{C}$. As for the total amount of acid sites, the normalized area beneath the curves offers the following relative order: MoSi-ME $>$ MoSi-SG > MoSi-IMP $>$ MoMg-SG $>$ MoAl-SG $>\mathrm{SiO}_{2}$. The order that can clearly be related to the specific surface area of the samples (see Table 1) since the sample with the greatest surface area, MoSi-ME, is the one that shows the 

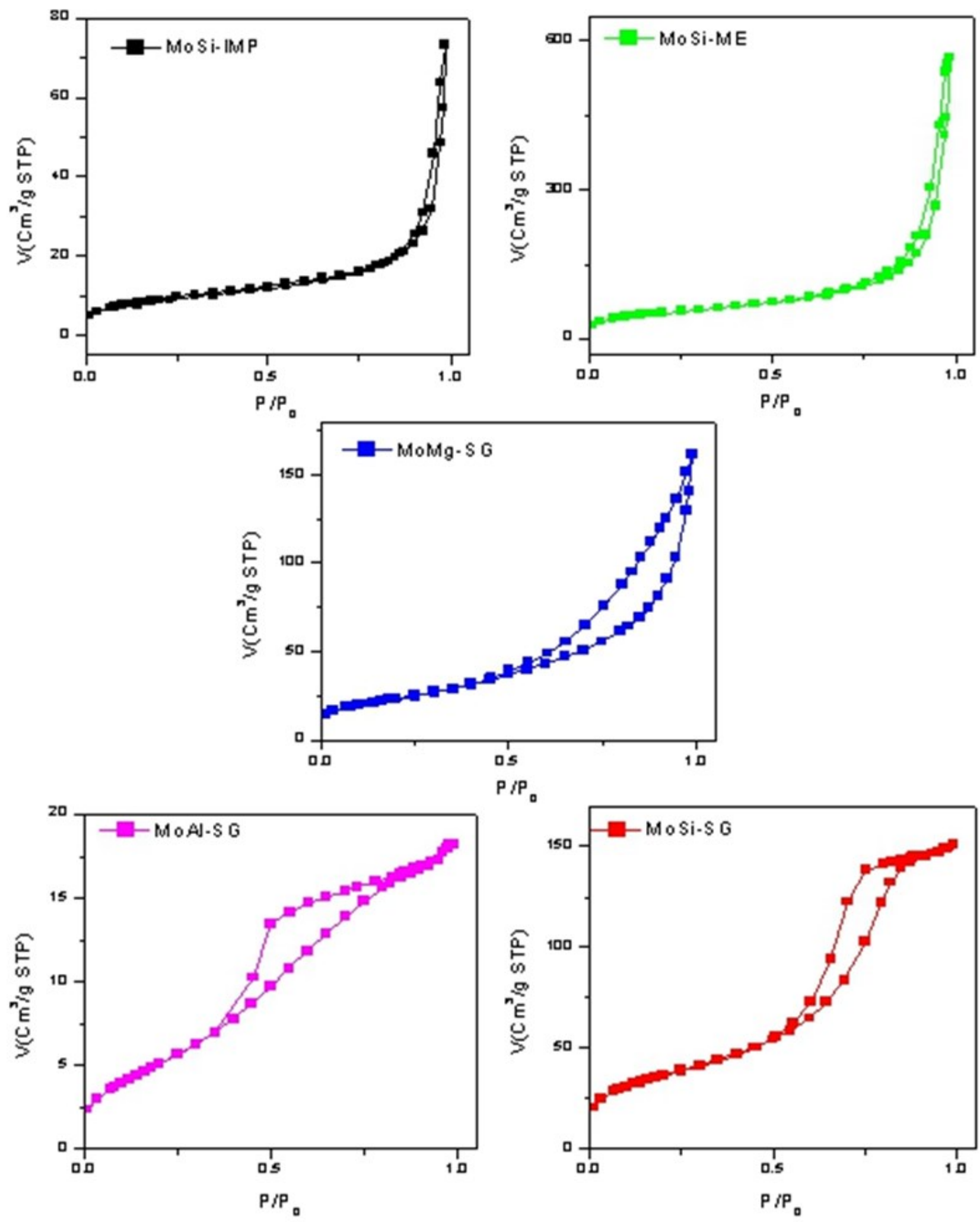

Figure 3. $\mathrm{N}_{2}$-sorption isotherms of the calcined samples: MoSi-SG, MoSi-ME, MoSi-IMP, MoAl-SG and $\mathrm{MoMg}-\mathrm{SG}$ 


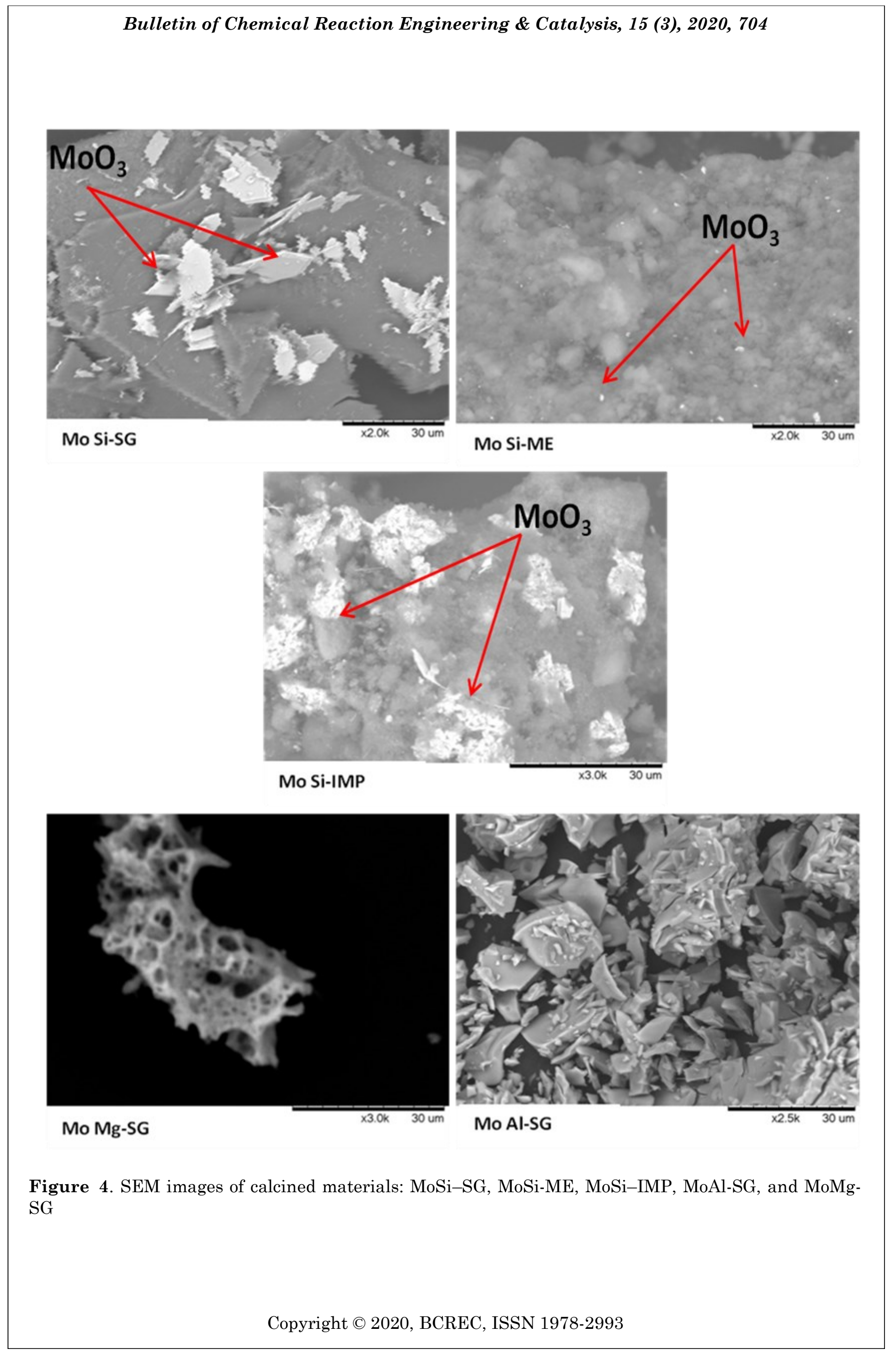




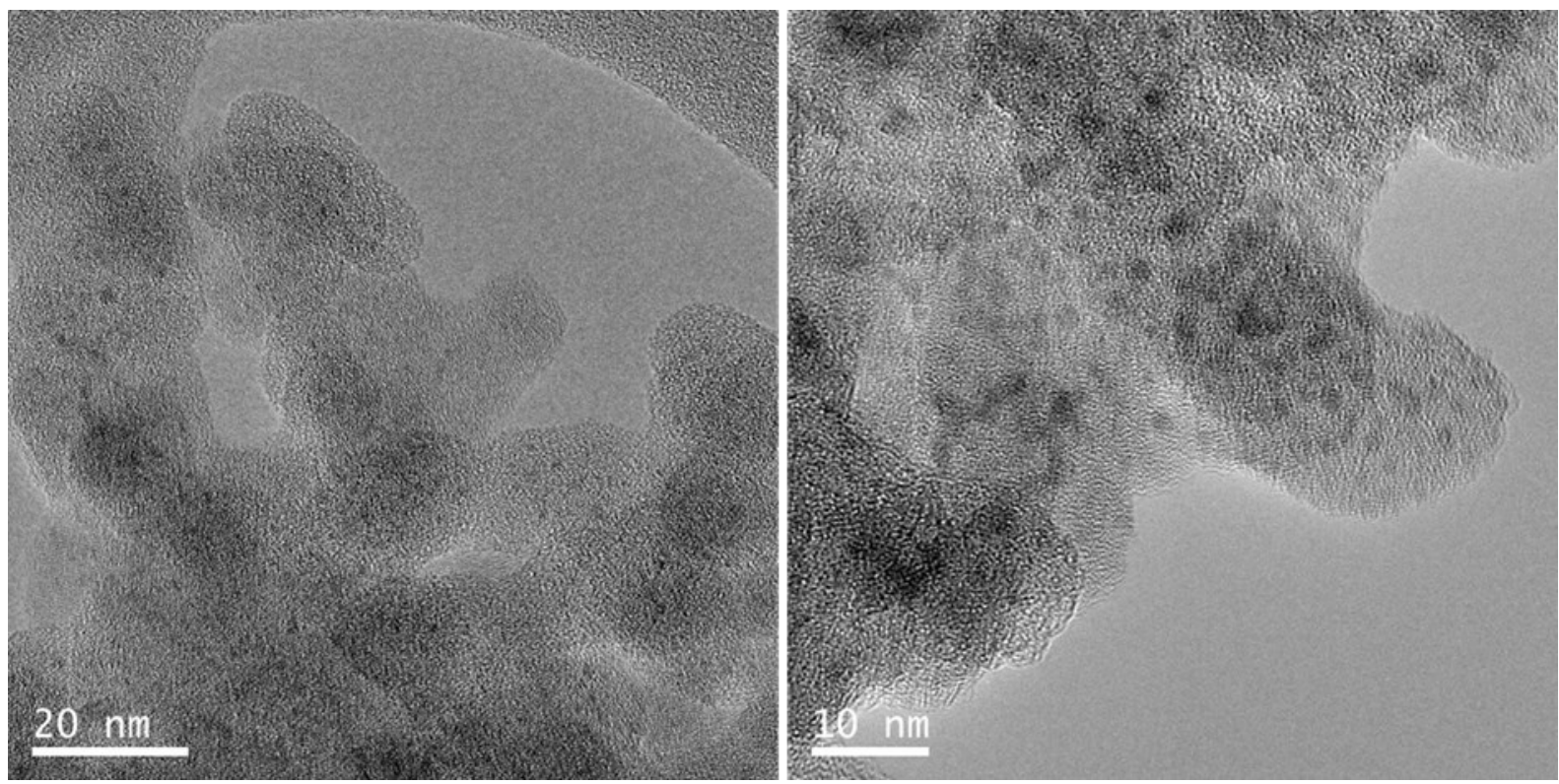

Figure 5.TEM images of the MoSi-ME sample
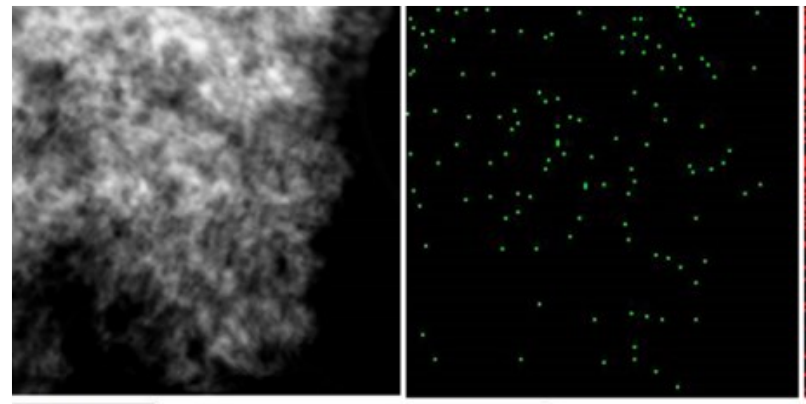

$200 \mathrm{~nm}$

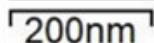

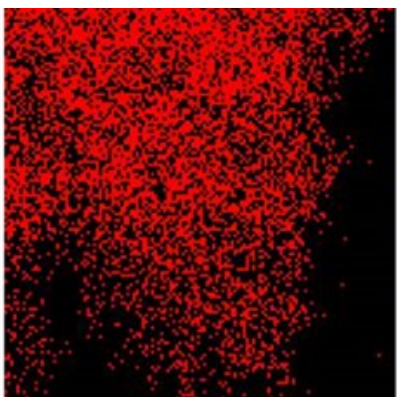

$200 \mathrm{~nm}$

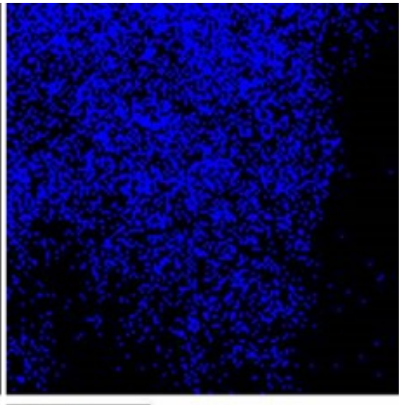

$\longdiv { 2 0 0 \mathrm { nm } }$

Figure 6. STEM dark field micrograph and corresponding EDX elemental mapping of MoSi-ME catalyst. Color code refers to the distribution of elements (Mo, green; $\mathrm{Si}$, red; O, blue)

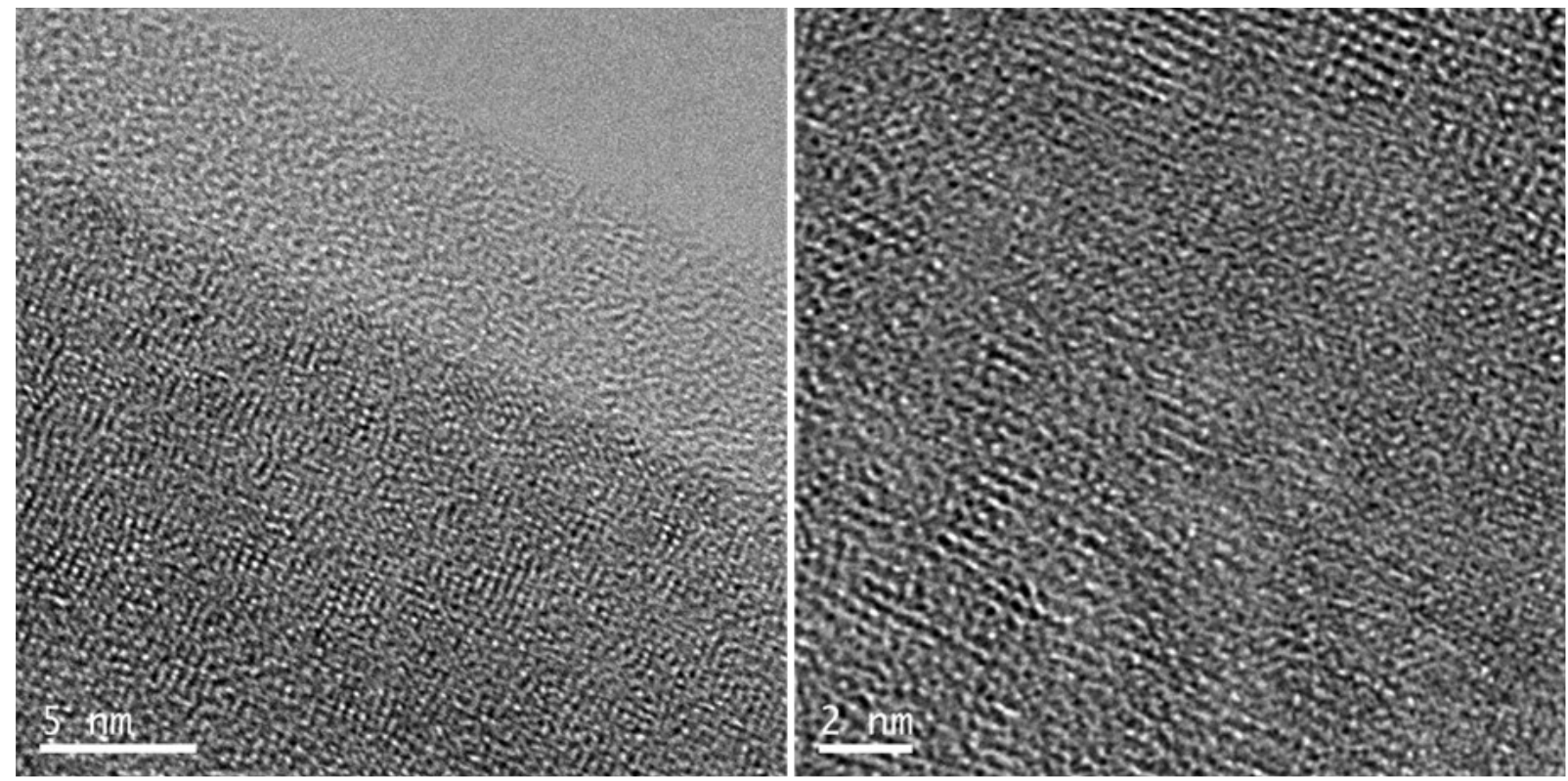

Figure 7. TEM images of the MoSi-SG sample. 


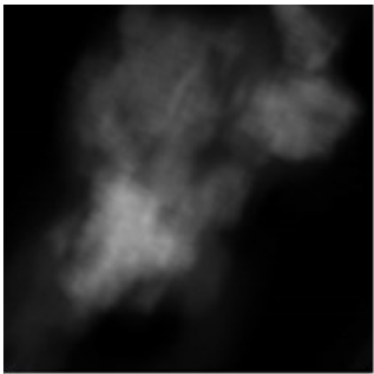

$100 \mathrm{~nm}$

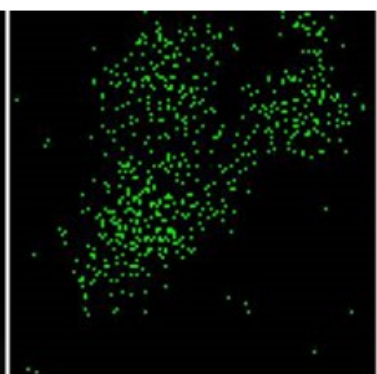

$100 \mathrm{~nm}$

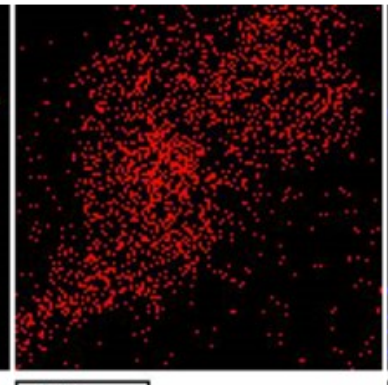

100nm

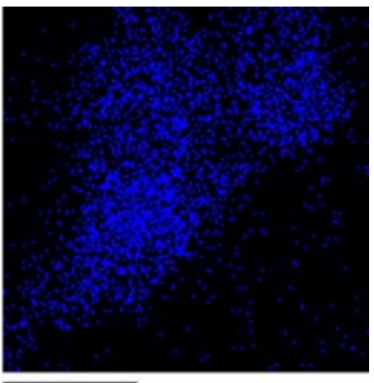

$100 \mathrm{~nm}$

Figure 8. STEM dark field microgragh and corresponding EDX elemental mapping of MoSi-SG catalyst. Color code refers to the distribution of elements (Mo, green; Si, red; O, blue).

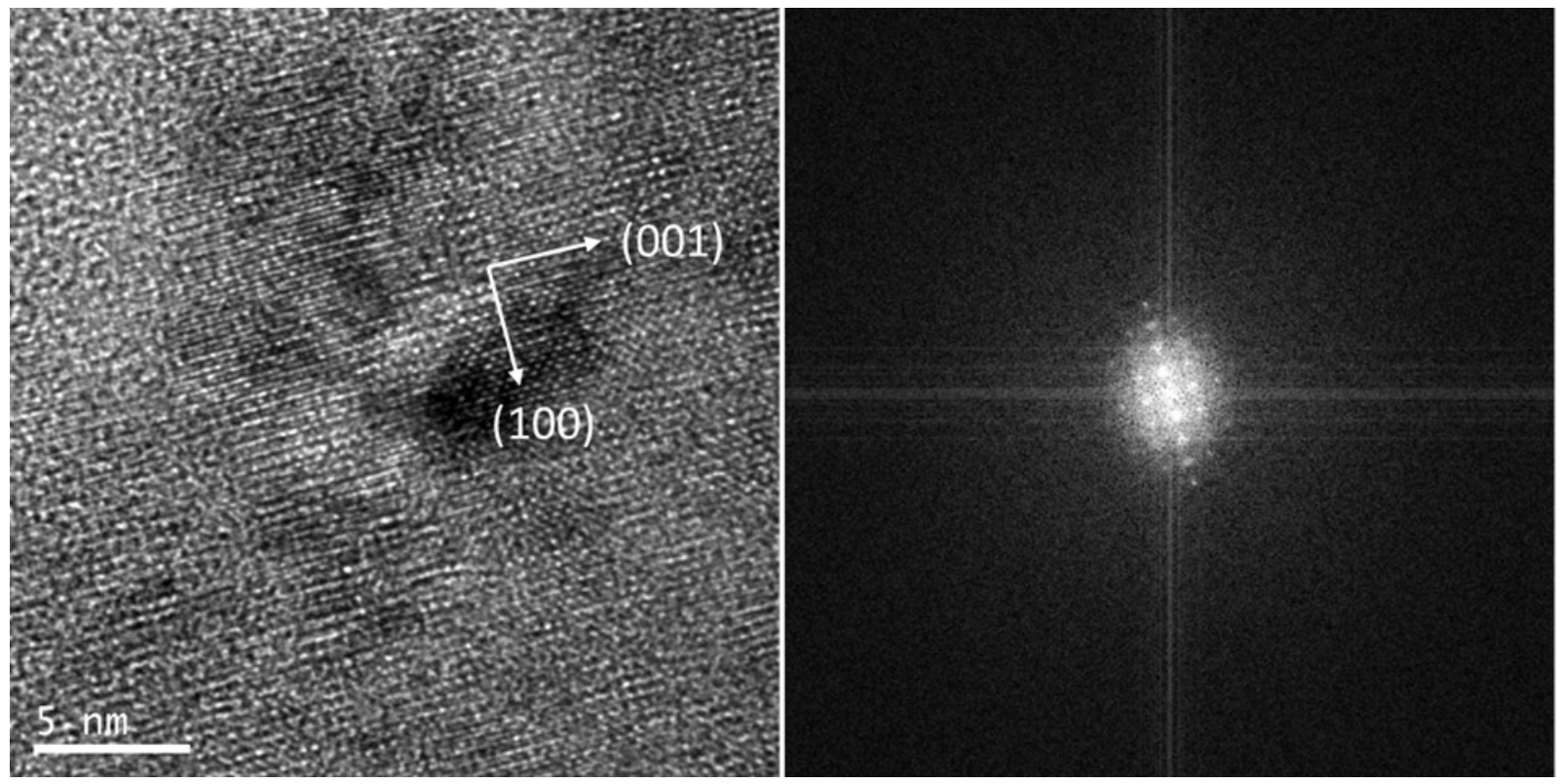

Figure 9. TEM image and FFT pattern of the MoSi-SG sample
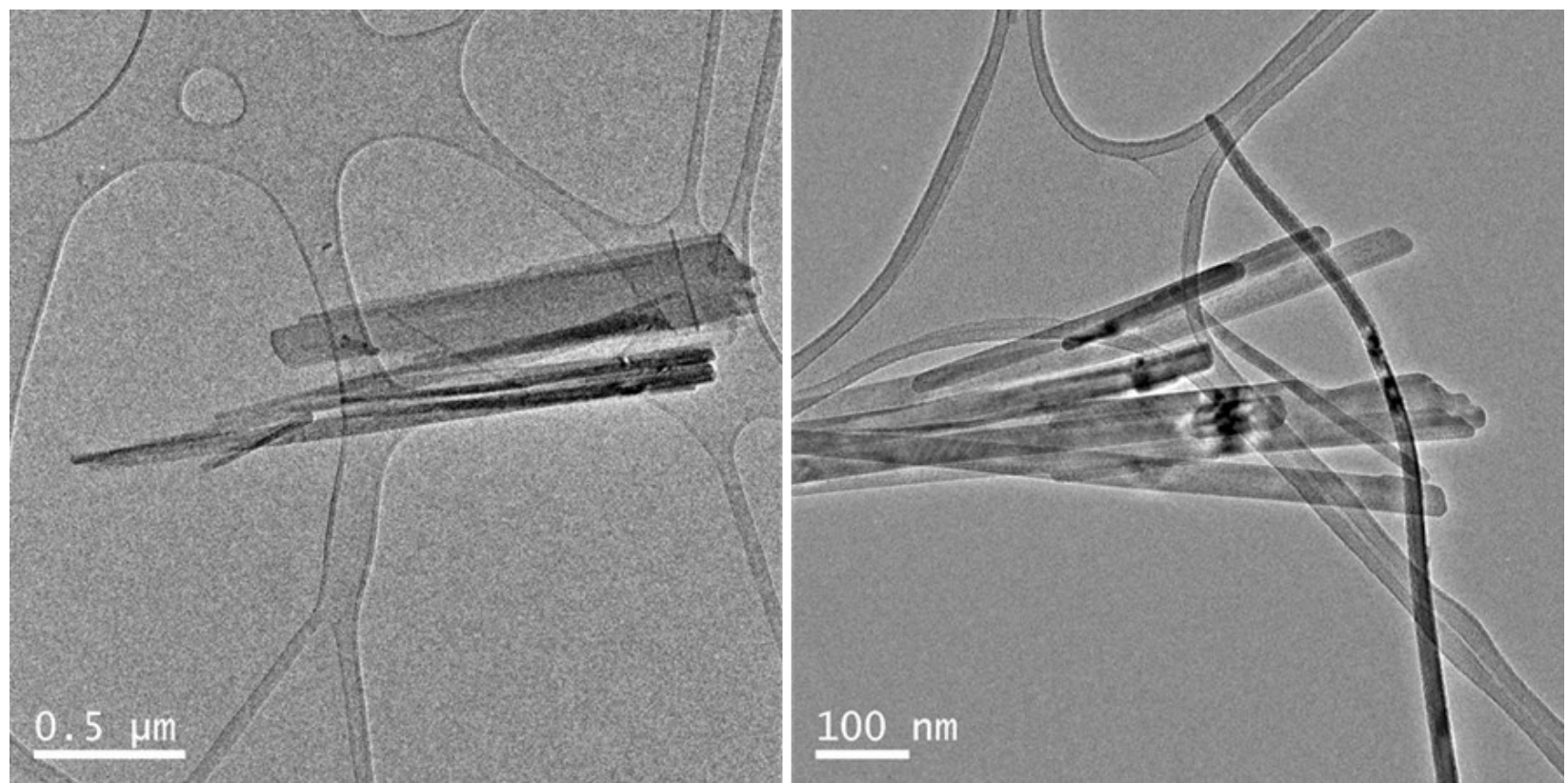

Figure 10. TEM images of the MoSi-SG sample 
greatest amount of acid sites, although all of them are weak acid sites.

\subsection{Biginelli Reaction}

Preliminary tests were carried out at 100 ${ }^{\circ} \mathrm{C}$, to optimize the operation conditions (catalyst amount and reaction temperature) of the Biginelli reaction, in the presence of MoAl-SG catalyst. With catalyst amount of 0.05 $\mathrm{g}$, the DHPM yield is about 15\% (entry 1 Table 2) but with increasing the catalyst mass to 0.1 , the obtained yield is twice (30\%) as high as the first. Whereas, the use of more higher catalyst weights (0.2 and $0.5 \mathrm{~g})$ has no significant effect on the DHPM yields (32 and 34\%, respectively). A similar evolution of the DHPM was obtained as function of the increase of reaction temperature (Table 3). So based on these results the optimum catalyst mass and reaction temperature chosen in the following Biginelli experiments will be an amount catalyst of $0.1 \mathrm{~g}$ and a reaction temperature of $100^{\circ} \mathrm{C}$.

The effect of reaction time on DHPM yield was also studied in the interval of 1-8 h (Figure 13) using MoSi-SG and MoAl-SG. The obtained results show that both systems have a different

Table 2. Effect of catalyst amount on the product yields. (Reaction conditions: benzaldehyde $\left(2 \times 10^{-3} \mathrm{~mol}\right)$, ethyl acetoacetate $\left(2 \times 10^{-3} \mathrm{~mol}\right)$, urea $\left(3 \times 10^{-3} \mathrm{~mol}\right)$, MoAl-SG and ethanol (solvent) for $3 \mathrm{~h}$ at $100{ }^{\circ} \mathrm{C}$. All products were characterized by ${ }^{1} \mathrm{H}$ NMR, ${ }^{13} \mathrm{C}$ NMR, and ATR)

\begin{tabular}{ccc}
\hline Entry & $\begin{array}{c}\text { Catalyst amount } \\
(\mathrm{g})\end{array}$ & $\begin{array}{c}\text { Yield } \\
(\%)\end{array}$ \\
\hline 1 & 0.05 & 15 \\
2 & 0.1 & 30 \\
3 & 0.2 & 32 \\
4 & 0.5 & 34 \\
\hline
\end{tabular}

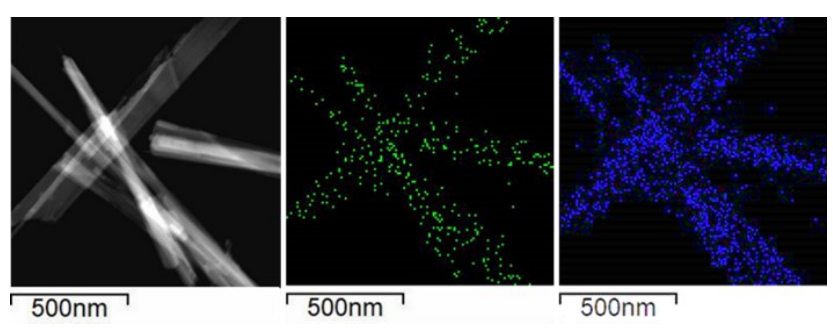

Figure 11. STEM dark field micrograph and corresponding EDX elemental mapping of MoSi-SG catalyst. Color code refers to the distribution of elements (Mo, green; O, blue). catalytic behavior. Thus, in the presence of MoSi-SG, the DHPM yield increases progressively from 30 to $99 \%$ with the reaction time from 1 to $6 \mathrm{~h}$. Beyond $6 \mathrm{~h}$, it decreases until $62 \%$. This DHPM yield decrease can be explained by the formation of DHP product via competitive Hantzsch reaction [55]. Whilst in the presence of MoAl-SG catalyst, the DHPM yield increases progressively from 7 to $84 \%$ with the reaction time. Thus, it can be concluded that for a reaction time of $6 \mathrm{~h}$, MoSi-SG is more efficient than MoAl-SG (99 against 67\% of DHPM yield).

Table 4 summarizes the obtained DHPM yields as a function of the catalyst nature and reaction time. The study was carried out with and free solvent. The reaction temperature was fixed at $100{ }^{\circ} \mathrm{C}$ and the catalyst amount at 0.1 g. The reaction did not take place in the absence of catalyst (entry 1). In the presence of $\mathrm{SiO}_{2}$ support, the DHPM yield is $<10 \%$ for a reaction time of $3 \mathrm{~h}$ (entry 2) and reaches $40 \%$

Table 3. Effect of the reaction temperature on the product yields. (Reaction conditions: benzaldehyde $\left(2 \times 10^{-3} \mathrm{~mol}\right)$, ethylacetoacetate $\left(2 \times 10^{-3}\right.$ mol), urea $\left(3 \times 10^{-3} \mathrm{~mol}\right)$, MoAl-SG (0.1 g) and ethanol (solvent) for $3 \mathrm{~h}$ at $100^{\circ} \mathrm{C}$. All products were characterized by ${ }^{1} \mathrm{H} \mathrm{NMR},{ }^{13} \mathrm{C} \mathrm{NMR}$, and ATR

\begin{tabular}{ccc}
\hline Entry & Temperature $\left({ }^{\circ} \mathrm{C}\right)$ & $\begin{array}{c}\text { Yield } \\
(\%)\end{array}$ \\
\hline 1 & 70 & 14 \\
2 & 80 & 22 \\
3 & 100 & 30 \\
4 & 120 & 35 \\
\hline
\end{tabular}

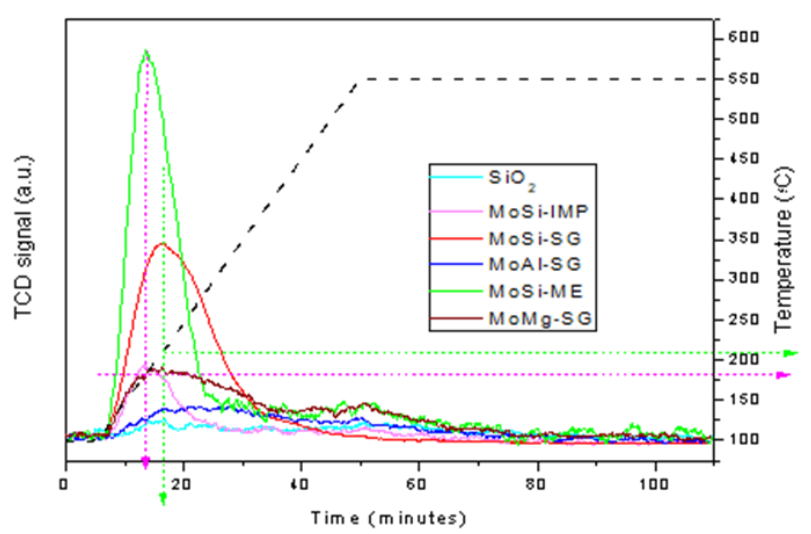

Figure 12. $\mathrm{NH}_{3}$-TPD curves of synthesized Mo supported catalysts 

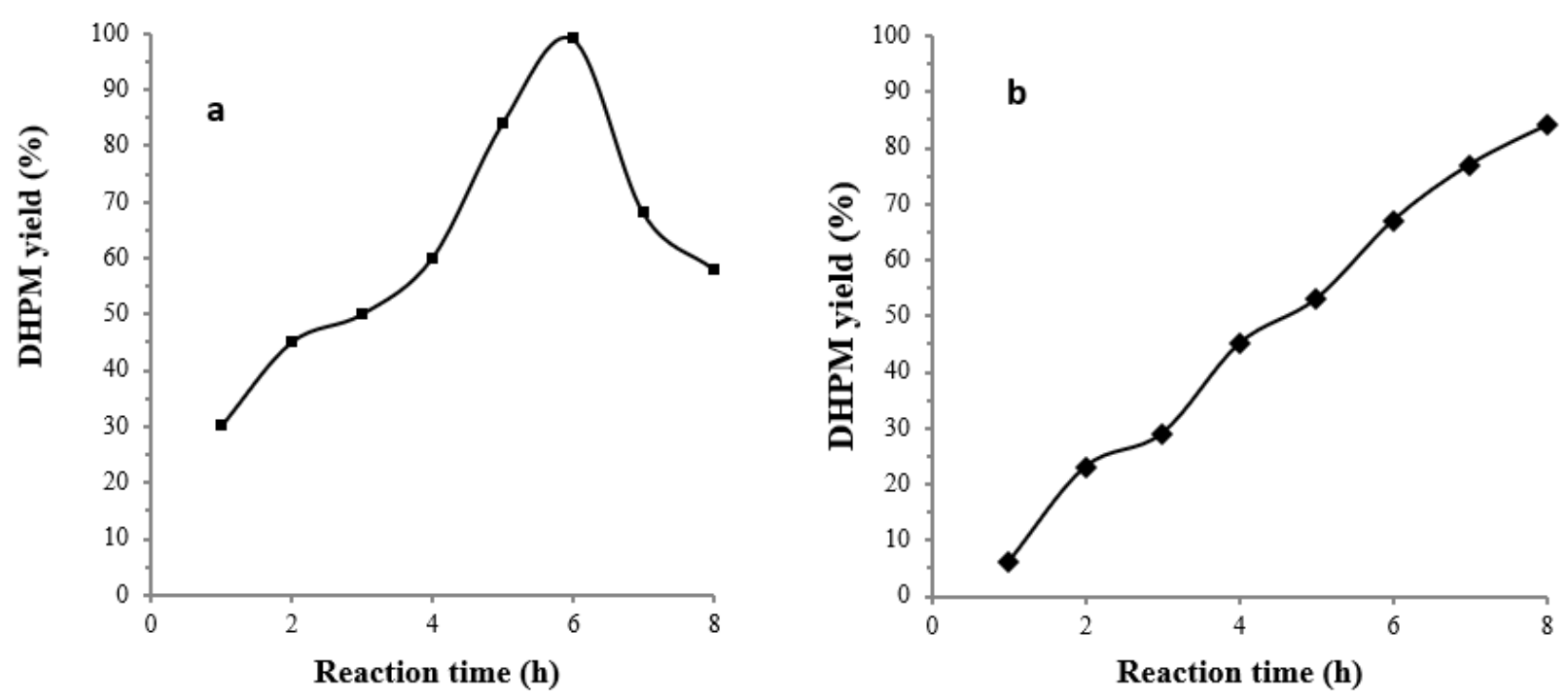

Figure 13. DHPM yield as a function of the reaction time a) MoSi-SG, b) MoAl-SG. (Reaction conditions: benzaldehyde $\left(2 \times 10^{-3} \mathrm{~mol}\right)$, ethyl acetoacetate $\left(2 \times 10^{-3} \mathrm{~mol}\right)$, urea $\left(3 \times 10^{-3} \mathrm{~mol}\right)$, ethanol us solvent .The reaction was performed at $100{ }^{\circ} \mathrm{C}$. All products are characterized by ${ }^{1} \mathrm{H}$ NMR and ${ }^{13} \mathrm{C}$ NMR)

Table 4. DHPM yields via Biginelli reaction. (Reaction conditions: benzaldehyde $\left(2 \times 10^{-3}\right.$ mol), ethyl acetoacetate $\left(2 \times 10^{-3} \mathrm{~mol}\right)$, urea $\left(3 \times 10^{-3} \mathrm{~mol}\right)$, ethanol us solvent. The reaction was performed at $100^{\circ} \mathrm{C}$. All products were characterized by ${ }^{1} \mathrm{H}$ NMR, ${ }^{13} \mathrm{C} \mathrm{NMR}$, and ATR)

\begin{tabular}{cclcc}
\hline Entry & Catalyst & Solvent & Time & Yields (\%) \\
\hline 1 & None & Ethanol & $6 \mathrm{~h}$ & - \\
2 & $\mathrm{SiO}_{2}$ & Ethanol & $3 \mathrm{~h}$ & $<10$ \\
3 & $\mathrm{SiO}_{2}$ & Ethanol & $6 \mathrm{~h}$ & 40 \\
4 & MoSi-SG & Ethanol & $3 \mathrm{~h}$ & 50 \\
5 & MoAl-SG & Ethanol & $3 \mathrm{~h}$ & 30 \\
6 & MoSi-SG & Ethanol & $6 \mathrm{~h}$ & 99 \\
7 & MoAl-SG & Ethanol & $6 \mathrm{~h}$ & 67 \\
8 & MoMg-SG & Ethanol & $3 \mathrm{~h}$ & - \\
9 & MoMg-SG & Ethanol & $6 \mathrm{~h}$ & 55 \\
10 & MoSi-ME & Ethanol & $3 \mathrm{~h}$ & 42 \\
11 & MoSi-IMP & Ethanol & $3 \mathrm{~h}$ & 36 \\
12 & MoSi-ME & Ethanol & $6 \mathrm{~h}$ & 94 \\
13 & MoSi-IMP & Ethanol & $6 \mathrm{~h}$ & 87 \\
14 & MoSi-SG & - & $30 \mathrm{~min}$ & 87 \\
15 & MoSi-ME & - & $30 \mathrm{~min}$ & 80 \\
16 & MoSi-IMP & - & $30 \mathrm{~min}$ & 75 \\
17 & MoMg-SG & - & $30 \mathrm{~min}$ & 60 \\
18 & MoAl-SG & - & $30 \mathrm{~min}$ & 70 \\
\hline
\end{tabular}


for a reaction time of $6 \mathrm{~h}$ (entry 3). The molybdenum incorporation, active species, in the system prepared by sol-gel method (MoSi-SG) permitted the reduction of the reaction time from 6 to $3 \mathrm{~h}$ and an increase of DHPM yield from 40 to $50 \%$ (entry 4 ). The replacement of silica by alumina (MoAl-SG) decreased the yield from 50 to $30 \%$ (entry 5) and from 99 to $67 \%$ (entries $6,7)$ after 3 and $6 \mathrm{~h}$ of reaction time respectively. In the case of the MoMg-SG system, the reaction did not take place after $3 \mathrm{~h}$ (entry 8 ) and the DHPM yield achieves 55\% after 6 h (entry 9).

The evolution of DHPM yield for a reaction time of 6 hours, depending on the nature of support, follows this sequence: MoSi-SG (99\%) $>$ MoAl-SG (67\%) > MoMg-SG (55\%). Indeed, based on this order, it could be suggested that the DHPM yield depends on the acidity of the used support which determined this order of acidity for the different oxides $\left(\mathrm{SiO}_{2}>\mathrm{Al}_{2} \mathrm{O}_{3}>\right.$ $\mathrm{MgO})$. On the other hand, the production of DHPM is also due to the presence of the active $\mathrm{aMoO}_{3}$ species of orthorhombic structure as confirmed by the XRD analysis. According to K Kouachi et al. [56], the use of only alumina support in the Biginelli reaction leads to a DHPM yield of $8 \%$ in the 10 hours of reaction while supporting active $\mathrm{MoO}_{3}$ phase onto $\mathrm{Al}_{2} \mathrm{O}_{3}$ support, increases significantly the yield of DHPMs to $87 \%$.

The high yield of DHPM obtained via the MoSi-SG sample could also be attributed to the formation of more homogeneous and highly dispersed $\mathrm{aMoO}_{3}$ species on the surface of $\mathrm{SiO}_{2}$, as demonstrated by SEM, TEM, and FFT analyses, compared to its other homologues. In addition, the most active sample (MoSi-SG) has the highest contribution of strong acid sites according to ammonia test results. Hence, the combination of these different parameters (structure, surface and acidity) could be at the origin of the observed results. Therefore, it can be concluded that the Biginelli reaction requires strong acid sites with the presence of highly dispersed orthorhombic structure $\mathrm{aMoO}_{3}$ species. In relation to acidity, our results agree with those of literature which reported that higher yields of DHPM in homogeneous phase, are obtained by using very strong mineral acids, such as $\mathrm{HCl}$ and $\mathrm{H}_{2} \mathrm{SO}_{4}$ [57].

The effect of the preparation method on the activity of the most efficient catalyst (MoSi) was also examined (Table 4). The entries 4, 10, and 11 shows that obtained DHPM yields with $\mathrm{SiO}_{2}$ as a support, are sensitive to preparation mode. Thus, the following sequence was observed: MoSi-SG (50\%) > MoSi-ME (42\%) > MoSi-IMP (36\%). These results confirm that the sol-gel method is the best one probably due to a better distribution and accessibility of the active sites by the substrates.

Concerning the solvent effect, it has been noted that in free solvent and with a reaction time of $30 \mathrm{~min}$, high DHPM yields were obtained in the presence of MoSi-SG (87\%), MoSi-ME (80\%), MoSi-IMP (75\%), MoAl-SG (70\%), and MoMg-SG (60\%); yields (60-87\%), superior to those obtained in the presence of ethanol and with a reaction time of $3 \mathrm{~h}(0$ $50 \%$ ). These results revealed the negative effect of the solvent on the Biginelli reaction. Indeed, ethanol could block some active acid sites of the catalyst, by behaving like a base, leading consequently to a decrease in active sites dedicated to substrates.

In addition to the influence of solvent, Kour et al. [58] studied the one-pot synthesis of 3,4dihydropyrimidin-2(1H)-ones using silica supported copper(II) chloride as heterogeneous catalyst, under two set of conditions: thermal (in free solvent) and microwave irradiations. It has been proved over this study that the operating conditions strongly affect the catalytic activity. So, with a catalyst mass of $0.05 \mathrm{~g}$, high production of DHPM estimated at 94 and $90 \%$ were obtained using respectively free solvent conditions and acetonitrile (microwave method).

Among the tested systems in the Biginelli reaction, MoSi-SG exhibits the best catalytic performance with $87 \%$ of DHPM yield and a reaction time of $30 \mathrm{~min}$, in free solvent. The obtained products obtained over this sample were characterized by ATR and ${ }^{1} \mathrm{H}$ and ${ }^{13} \mathrm{C}$ NMR. The physical data for 5-ethoxycarbonyl-4phenyl-6-methyl-3,4-dihydropyridin-2(1H)-one (DHPM) are:

Tfus: $202-206^{\circ} \mathrm{C}$ Lit $202-204{ }^{\circ} \mathrm{C}$ [33]; RMN $1 \mathrm{H}$ (400MHz DMSO-d6): $8 \mathrm{H} 9.21(\mathrm{~s}, 1 \mathrm{H}, \mathrm{NH}) ; 7.75$ $(\mathrm{s}, 1 \mathrm{H}, \mathrm{NH}) ; 7.34(\mathrm{~m}, 5 \mathrm{H}, \mathrm{CH}$ arom); $5.15(\mathrm{~d}, 1 \mathrm{H}, 3$ $\mathrm{J}=3.2, \quad \mathrm{CH}) ; \quad 4.00 \quad \mathrm{q}, 2 \mathrm{H}, \quad 3 \mathrm{~J}=7.1, \mathrm{CH} 2) ; 2.25$ (s,3H,CH3); 1.11 (t, 3H, 3J=7.1,CH3); RMN 13C (DMSO-d6): $\quad \delta \mathrm{C} \quad 165.34 \quad$ (COOEt); 152.14(C2); 148.38(C6); [144.87;128.4; 127.28; 126.25] C arom; 99.25(C5); 59.2 (OCH2CH3); 53.93 (C4); 17.79 (CH3);14.09 (OCH2CH3);

ATR $\lambda_{\max }: 3106(\mathrm{NH}) ; 1705(\mathrm{C}=\mathrm{O}$ ester); 1627 $(\mathrm{C}=\mathrm{C}$ and $\mathrm{C}=\mathrm{O}) ; 1216(\mathrm{C}-\mathrm{N}) \mathrm{cm}^{-1}$. 


\section{Conclusions}

The synthesis of dihydropyrimidin-2(1H)one via the Biginelli reaction was carried out in the presence of molybdenum metal oxides $\left(\mathrm{MgO}, \mathrm{Al}_{2} \mathrm{O}_{3}\right.$, and $\left.\mathrm{SiO}_{2}\right)$ catalysts prepared using different methods (impregnation, sol-gel, microemulsion). Regardless, the preparation procedure and the metal oxide, the structural and surface analyses revealed for the elaborated samples, the formation of $\mathrm{aMoO}_{3}$ phase with an orthorhombic structure and the existence of molybdenum microdomains. However, the form and the size of the Mo species as well as their catalytic activity, are very sensitive to the synthesis method and nature of meal oxide. The reactivity tests in the Biginelli reaction showed that the use of $\mathrm{SiO}_{2}$ oxide and sol-gel method leads to the most efficient catalyst (MoSi-SG) which exhibited a DHPM yield of $87 \%$ under the following operating conditions: $0.1 \mathrm{~g}$ of catalyst, a reaction time of $30 \mathrm{~min}$ and a reaction temperature of $100{ }^{\circ} \mathrm{C}$ in the solvent-free test. The best catalytic performances obtained over the MoSi-SG sample are strongly assigned to the formation of more homogenous and highly dispersed $\mathrm{aMoO}_{3}$ species on $\mathrm{SiO}_{2}$ surface, possessing a high contribution of strong acid sites, compared to the other catalysts. Based on these results, the Biginelli synthesis performed in heterogeneous phase mode seems to be a very interesting process, allowing a simple separation of the product-catalyst and therefore the recovery of the latter for possible reuses. Moreover, the absence of solvent avoided the harmful products use.

\section{Acknowledgments}

This research was financed by Ministère de l'Enseignement Supérieur et de la Recherche Scientifique (MESRS), Alger, Algérie, and partially financed by Spanish Agencia Estatal de Investigación (AEI) y el Fondo Europeo de Desarrollo Regional (FEDER), UE (project CTQ2017-89443-C3-3-R). C.L.-O. thanks the MECD of Spain for a FPU predoctoral grant FPU16/05131.

\section{References}

[1] Kappe, C.O. (1993). 100 years of the Biginelli dihydropyrimidine synthesis. Tetrahedron, 49, 6937-6963

[2] Kappe, C.O., Fabian, W.M.F., Semones, M.A. (1997). Tonformational analysis of 4-aryl-d dihydropyrimidine calcium channel modulators. a comparison of $\mathrm{Ab}$ lnitio, semiempirical and x-ray crystallographic studies. Tetrahedron, 53, 2803-2816.

[3] Kappe, C.O. (2000). Recent advances in the Biginelli dihydropyrimidine synthesis. New tricks from an old dog. Accounts of Chemical Research, 33, 879-888.

[4] Atwal, K.S., Rovnyak, G.C., Kimball, S.D., Floyd, D.M., Moreland, S., Swanson, B.N., Malley, M.F. (1990). Dihydropyrimidine calcium channel blockers. II. 3-Substituted-4a r y l - 1, 4-d i h y d r o - 6 - m e t h y l - 5pyrimidinecarboxylic acid esters as potent mimics of dihydropyridines. Journal of Medicinal Chemistry, 33, 2629-2635.

[5] Atwal, K.S., Rovnyak, G.C., O'Reilly, B.C., Schwartz, J. (1989). Substituted 1, 4dihydropyrimidines. 3. Synthesis of selectively functionalized 2-hetero-1, 4dihydropyrimidines. The Journal of Organic Chemistry, 54, 5898-5907.

[6] Biginelli, P. (1893). Aldehyde-urea derivatives of aceto-and oxaloacetic acids. Gazz. Chim. Ital., 23 , 360-413.

[7] Liu, C., Wang, J., Li, Y. (2006). One-pot synthesis of 3, 4-dihydropyrimidin-2 (1H)-(thio) ones using strontium (II) nitrate as a catalyst. Journal of Molecular Catalysis A: Chemical, 258, 367-370.

[8] Hu, E.H., Sidler, D.R., Dolling, U.-H. (1998). Unprecedented catalytic three component one-pot condensation reaction: an efficient synthesis of 5-alkoxycarbonyl-4-aryl-3, 4dihydropyrimidin-2 (1H)-ones. The Journal of Organic Chemistry, 63, 3454-3457.

[9] Suzuki, I., Suzumura, Y., Takeda, K. (2006). Metal triflimide as a Lewis acid catalyst for Biginelli reactions in water. Tetrahedron Letters, 47(45), 7861-7864.

[10] Zhao, S.-Y., Chen, Z.-Y., Wei, N., Liu, L., Han, Z.-B. (2019). Highly Efficient Cooperative Catalysis of Single-Site Lewis Acid and Brønsted Acid in a Metal-Organic Framework for the Biginelli Reaction. Inorganic Chemistry, 58(12), 7657-7661.

[11] Zhang, H., Zhou, Z., Yao, Z., Xu, F., Shen, Q. (2009). Efficient synthesis of pyrimidinone derivatives by ytterbium chloride catalyzed Biginelli-type reaction under solvent-free conditions. Tetrahedron Letters, 50, 1622-1624.

[12] Heravi, M.M., Behbahani, F.K., Oskooie, H.A. (2008). Ferric Perchlorate Catalyzed One-pot

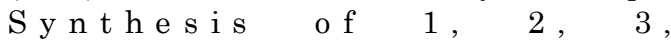
4-Tetrahydro-2-pyrimidinones and-thiones: an Expedient Protocol for the Biginelli Reaction. Chinese Journal of Chemistry, 26, 22032206. 
[13] Narsaiah, A.V., Reddy, A.R., Yadav, J. (2011). Samarium triflate-catalyzed Biginelli condensation: An improved method for the synthesis of 3, 4-dihydropyrimidin-2 (1H)-ones. Synthetic Communications, 41, 2794-2799.

[14] Narsaiah, A.V., Reddy, A.R., Yadav, J. (2011). Samarium triflate-catalyzed Biginelli condensation: An improved method for the synthesis of 3, 4-dihydropyrimidin-2 (1H)-ones. Synthetic Communications, 41(18), 2794-2799.

[15] Nagarajan, S., Shaikh, T. M., Kandasamy, E. (2015). Synthesis of 1-alkyl triazolium triflate room temperature ionic liquids and their catalytic studies in multi-component Biginelli reaction. Journal of Chemical Sciences, 127, 1539-1545.

[16] Wang, Y., Yu, J., Yang, H., Miao, Z., Chen, R. (2011). Solvent-free Biginelli reaction: A green method for the synthesis of 3, 4dihydropyrimidin-2-ones catalyzed by protic acids in large-scale. Letters in Organic Chemistry, 8(4), 264-267.

[17] Takale, S., Parab, S., Phatangare, K., Pisal, R., Chaskar, A. (2011). IBX in aqueous medium: a green protocol for the Biginelli reaction. Catalysis Science \& Technology, 1, 1128-1132.

[18] Fazaeli, R., Tangestaninejad, S., Aliyan, H., Moghadam, M. (2006). One-pot synthesis of dihydropyrimidinones using facile and reusable polyoxometalate catalysts for the Biginelli reaction. Applied Catalysis A: General, 309, 44-51.

[19] Rafiee, E., Shahbazi, F. (2006). One-pot synthesis of dihydropyrimidones using silicasupported heteropoly acid as an efficient and reusable catalyst: Improved protocol conditions for the Biginelli reaction. Journal of Molecular Catalysis A: Chemical, 250, 57-61.

[20] Shen, Z.-L., Xu, X.-P., Ji, S.-J. (2010). Brønsted base-catalyzed one-pot threecomponent Biginelli-type reaction: An efficient synthesis of $4,5,6$-triaryl-3, 4dihydropyrimidin-2 $(1 \mathrm{H})$-one and mechanistic study. The Journal of Organic Chemistry, 75, 1162-1167.

[21] Tamaddon, F., Razmi, Z., Jafari, A.A. (2010). Synthesis of 3, 4-dihydropyrimidin-2 (1H)ones and 1,4-dihydropyridines using ammonium carbonate in water. Tetrahedron Letters, 51, 1187-1189.

[22] Heravi, M.M., Bakhtiari, K., Bamoharram, F.F. (2006). 12-Molybdophosphoric acid: A recyclable catalyst for the synthesis of Biginellitype 3,4-dihydropyrimidine-2 (1H)-ones. Catalysis Communications, 7, 373-376.

[23] Khabazzadeh, H., Saidi, K., Sheibani, H. (2008). Highly efficient conversion of aromatic acylals to 3,4-dihydropyrimidinones: a new protocol for the Biginelli reaction. Arkivoc, 15, $34-41$

[24] Ahmed, B., Khan, R.A., Keshari, M. (2009). An improved synthesis of Biginelli-type compounds via phase-transfer catalysis. Tetrahedron Letters, 50, 2889-2892.

[25] Dadhania, A. N., Patel, V. K., \& Raval, D. K. (2012). A facile approach for the synthesis of 3,4-dihydropyrimidin-2-(1H)-ones using a microwave promoted Biginelli protocol in ionic liquid. Journal of Chemical Sciences, 124, 921-926.

[26] Mahato, B.N., Krithiga, T. (2019). Mesoporous $\mathrm{ZnO} / \mathrm{AlSBA}-15$ (7) Nanocomposite as An Efficient Catalyst for Synthesis of 3,4dihydropyrimidin-2 (1H)-one via Biginelli Reaction and Their Biological Activity Study. Bulletin of Chemical Reaction Engineering \& Catalysis, 14, 634-645.

[27] Chaudhary, G.R., Bansal, P., Mehta, S. (2014). Recyclable CuS quantum dots as heterogeneous catalyst for Biginelli reaction under solvent free conditions. Chemical Engineering Journal, 243, 217-224.

[28] Gupta, R., Paul, S., Gupta, R. (2007). Covalently anchored sulfonic acid onto silica as an efficient and recoverable interphase catalyst for the synthesis of 3,4 dihydropyrimidinones/thiones. Journal of Molecular Catalysis A: Chemical, 266, 50-54.

[29] Umbarkar, S., Biradar, A., Mathew, S., Shelke, S., Malshe, K., Patil, P., Dagde, S., Niphadkar, S., Dongare, M. (2006). Vapor phase nitration of benzene using mesoporous $\mathrm{MoO}_{3} / \mathrm{SiO}_{2}$ solid acid catalyst. Green Chemistry, 8, 488-493.

[30] Amrute, A.P., Bordoloi, A., Lucas, N., Palraj, K., Halligudi, S. (2008). Sol-Gel Synthesis of $\mathrm{MoO}_{3} / \mathrm{SiO}_{2}$ Composite for Catalytic Application in Condensation of Anisole with Paraformaldehyde. Catalysis Letters, 126, 286-292.

[31] Klicpera, T., Zdražil, M. (2001). High surface area $\mathrm{MoO}_{3} / \mathrm{MgO}$ : preparation by reaction of $\mathrm{MoO}_{3}$ and $\mathrm{MgO}$ in methanol or ethanol slurry and activity in hydrodesulfurization of benzothiophene. Applied Catalysis A: General, 216, 41-50.

[32] Ma, X., Gong, J., Wang, S., Gao, N., Wang, D., Yang, X., He, F. (2004). Reactivity and surface properties of silica supported molybdenum oxide catalysts for the transesterification of dimethyl oxalate with phenol. Catalysis Communications, 5, 101-106.

[33] Jain, S.L., Prasad, V., Sain, B. (2008). Alumina supported $\mathrm{MoO}_{3}$ : An efficient and reusable heterogeneous catalyst for synthesis of 3, 4dihydropyridine-2 $(1 \mathrm{H})$-ones under solvent free conditions. Catalysis Communications, 9, 499-503 
[34] Jadhav, S., Anandgaonker, P.L., Kulkarni, G., Gaikwad, S.T., Rajbhoj, A.S. (2014). Microwave-assisted one-pot synthesis of octahydroquinazolinone derivatives using molybdenum oxide nanoparticles in solvent-free condition. Journal of Cluster Science, 25, 1389-1399.

[35] Thuadaij, N., Nuntiya, A. (2008). Preparation of nanosilica powder from rice husk ash by precipitation method. Chiang Mai Journal of Science, 35(1), 206-211.

[36] Lietti, L., Ramis, G., Busca, G., Bregani, F., Forzatti, P. (2000). Characterization and reactivity of $\mathrm{MoO}_{3} / \mathrm{SiO}_{2}$ catalysts in the selective catalytic oxidation of ammonia to $\mathrm{N}_{2}$. Catalysis Today, 61, 187-195.

[37] Biermann, J., Janssen, F., De Boer, M., Van Dillen, A., Geus, J., Vogt, E. (1990). Molybdena on silica catalysts: selective catalytic oxidation of ammonia to nitrogen over $\mathrm{MoO}_{3}$ on $\mathrm{SiO}_{2}$ catalysts. Journal of Molecular Catalysis, 60, 229-238.

[38] Jia, C., Massiani, P., Barthomeuf, D. (1993). Characterization by infrared and nuclear magnetic resonance spectroscopies of calcined beta zeolite. Journal of the Chemical Society, Faraday Transactions, 89, 3659-3665.

[39] Kido, A., Iwamoto, H., Azuma, N., Ueno, A. (2002). Effects of catalyst heating rates upon the activity of silica-supported silicomolybdic acid catalysts for methane partial oxidation. Catalysis Surveys from Asia, 6(1-2), 45-53

[40] Lippincott, E.R., Van Valkenburg, A., Weir, C.E. Bunting, E.N. (1958). Infrared studies on polymorphs of silicon dioxide and germanium dioxide. J. Res. Nat. Bureau of Standards, 61, 61-70.

[41] Rocchiccioli-Deltcheff, C., Amirouche, M., Hervé, G., Fournier, M., Che, M., Tatibouët, J.-M. (1990). Structure and catalytic properties of silica-supported polyoxomolybdates: II. Thermal behavior of unsupported and silicasupported 12-molybdosilicic acid catalysts from IR and catalytic reactivity studies. Journal of Catalysis, 126, 591-599

[42] Skupiński, W., Malesa, M. (2002). An infrared study on the $\mathrm{MoO}_{3} / \mathrm{SiO}_{2}$ catalytic system employed in toluene nitration. Appl. Catal. A: Gen. 236223-234.

[43] El Shafei, G.M., Mokhtar, M. (1995). Interaction between molybdena and silica: FT-IR/PA studies of surface hydroxyl groups and pore structure assessment. Colloids and Surfaces A: Physicochemical and Engineering Aspects, 94(2-3), 267-277

[44] Nasrollahzadeh, M., Issaabadi, Z., Sajadi, S. M. (2018). Green synthesis of a $\mathrm{Cu} / \mathrm{MgO}$ nanocomposite by Cassytha filiformis L. extract and investigation of its catalytic activity in the reduction of methylene blue, congo red and nitro compounds in aqueous media. $R S C$ Advances, 8, 3723-3735.

[45] Nyquist, R.A., Ronald, O. (1971). Kagel, Infrared Spectra of Inorganic Compounds. Academic Press, New York and London-1971 (971), 64, 65.

[46] Smith, M., Zhang, L., Driscoll, S., Ozkan, U. (1993). Effect of surface species on activity and selectivity of $\mathrm{MoO}_{3} / \mathrm{SiO}_{2}$ catalysts in partial oxidation of methane to formaldehyde. Catalysis Letters, 19, 1-15.

[47] Xu, S., Zhao, R., Wang, X. (2004). Highly coking resistant and stable $\mathrm{Ni} / \mathrm{Al}_{2} \mathrm{O}_{3}$ catalysts prepared by W/O microemulsion for partial oxidation of methane. Fuel Process. Technol., $86,123-133$

[48] Yahi, N., Menad, S., Rodríguez-Ramos, I. (2015). Dry reforming of methane over $\mathrm{Ni} / \mathrm{CeO}_{2}$ catalysts prepared by three different methods. Green Pocess. Synth., 4, 479-486.

[49] Thommes, M., Kaneko, K., Neimark, A.V., Olivier, J.P., Rodriguez-Reinoso, F., Rouquerol, J., Sing, K.S. (2015). Physisorption of gases, with special reference to the evaluation of surface area and pore size distribution (IUPAC Technical Report). Pure and Applied Chemistry, 87(9-10), 1051-1069.

[50] Chen, Y., Lu, C., Xu, L., Ma, Y., Hou, W., Zhu, J.-J. (2010). Single-crystalline orthorhombic molybdenum oxide nanobelts: synthesis and photocatalytic properties. Cryst EngComm, 12, 3740-3747.

[51] Bouzidi, A., Benramdane, N., Tabet-Derraz, H., Mathieu, C., Khelifa, B., Desfeux, R. (2003). Effect of substrate temperature on the structural and optical properties of $\mathrm{MoO}_{3}$ thin films prepared by spray pyrolysis technique. Materials Science and Engineering: B, 97, 58.

[52] Rao, M., Ravindranadh, K., Kasturi, A., Shekhawat, M. (2013). Structural stoichiometry and phase transitions of $\mathrm{MoO}_{3}$ thin films for solid state microbatteries. Research Journal of Recent Sciences, 2277, 67-73

[53] Lima, D.S., Perez-Lopez, O.W. (2019). Catalytic conversion of glycerol to olefins over Fe, $\mathrm{Mo}$, and $\mathrm{Nb}$ catalysts supported on zeolite ZSM-5. Renewable Energy, 136, 828-836.

[54] Obeso-Estrella, R., Fierro, J., De Leon, J.D., Fuentes, S., Alonso-Nuñez, G., Lugo-Medina, E., Zepeda, T. (2018). Effect of partial Mo substitution by W on HDS activity using sulfide $\mathrm{CoMoW} / \mathrm{Al}_{2} \mathrm{O}_{3}-\mathrm{TiO}_{2}$ catalysts. Fuel, 233, 644-657.

[55] Tamaddon, F., Moradi, S. (2013). Controllable selectivity in Biginelli and Hantzsch reac- 
tions using nano-ZnO as a structure base catalyst. Journal of Molecular Catalysis A: Chemical, 370, 117-122.

[56] Kouachi, K., Lafaye, G., Pronier, S., Bennini, L., Menad, S. (2014). Mo/ $/ \mathrm{Al}_{2} \mathrm{O}_{3}$ catalysts for the Biginelli reaction. Effect of Mo loading. Journal of Molecular Catalysis A: Chemical, 395, 210-216.

[57] Hassani, Z., Islami, M.R., Kalantari, M. (2006). An efficient one-pot synthesis of octahydroquinazolinone derivatives using catalytic amount of $\mathrm{H}_{2} \mathrm{SO}_{4}$ in water. Bioorganic \& Medicinal Chemistry Letters, 16, 4479-4482.
[58] Kour, G., Gupta, M., Paul, S., Gupta, V.K. (2014). $\mathrm{SiO}_{2}-\mathrm{CuCl}_{2}$ : An efficient and recyclable heterogeneous catalyst for one-pot synthesis of 3,4-dihydropyrimidin-2 (1H)ones. Journal of Molecular Catalysis A: Chemical, 392, 260-269. 